\title{
Radiologie im Nationalsozialismus - Projekt tourt durch die Medizinischen Fakultäten
}

\section{Radiologie im Nationalsozialismus in Israel \\ $\nabla$}

Im April 2015 wurde die Ausstellung Radiologie im Nationalsozialismus an der Medizinischen Fakultät der Universität Tel Aviv eröffnet. Die Ausstellung kam auf Betreiben des Präsidenten der Israelischen Röntgengesellschaft (ISRA) nach Israel und wurde eigens hierfür in Iwrit übersetzt. Seitdem wurden die Tafeln an einer ganzen Reihe medizinischer Fakultäten in Israel gezeigt; unsere Bilder zeigen die Ausstellung an Bar-Ilan-Fakultät in Galiläa. In Deutschland wird das Projekt aktuell in Tübingen ausgestellt und demnächst am Medizinhistorischen Institut in Kiel.

\section{Ausstellungseröffnung in Kiel $\nabla$}

Vom 13. Oktober 2016 bis Mitte April des kommenden Jahres wird Radiologie im Nationalsozialismus in der Medizin- und Pharmaziehistorischen Sammlung Kiel zu sehen sein.

Eröffnet wurde die Ausstellung vom Dekan der Medizinischen Fakultät, Prof. Ulrich Stephani, Grußworte hielten Prof. Jürgen Dunst, Direktor der Klinik für Strahlentherapie und Prof. Olav Jansen, Direktor der Klinik für Radiologie und Neuroradiologie. Dr. Mathias Schmidt, Institut für Geschichte, Theorie und Ethik der Medizin an der RWTH Aachen, hielt den Eröffnungsvortrag Radiologie im „Dritten Reich“.

Kiel ist der nunmehr neunte Ausstellungsort in Deutschland, die Ausstellung wurde darüber hinaus in einer hebräischen Übersetzung in Medizinischen Fakultäten in Israel gezeigt.

Aktuelle Informationen über Ausstellungstermine finden Sie im Internet unter www.drg.de

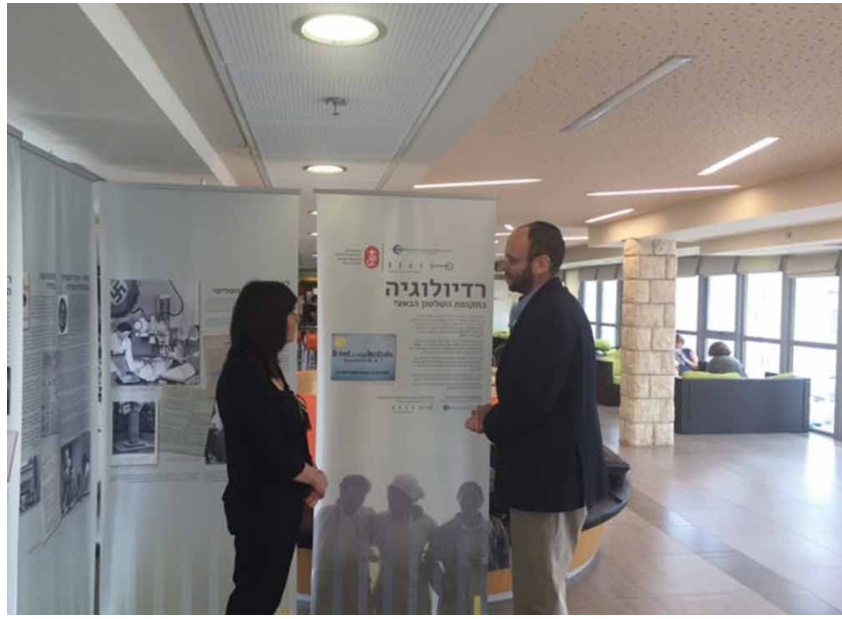

Die Ausstellung in Galiläa.

Copyright: Sosna

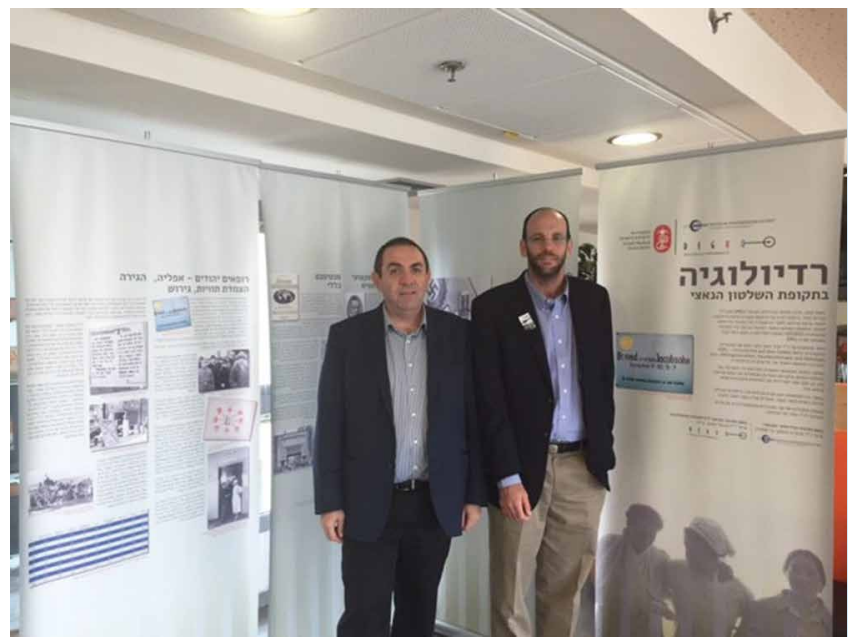

Prof. Dr. Jakob Sosna (links) mit dem Übersetzer der Tafeln und Koordinator der Wanderausstellung, Dr. Matt Fox. Copyright: Sosna

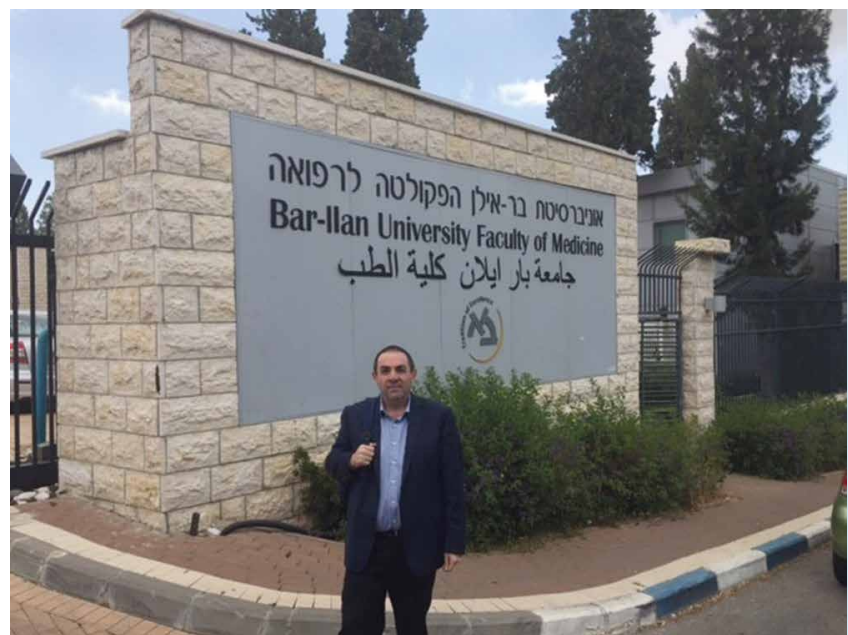

Prof. Jakob Sosna vor Fakultätsgebäude der Bar-Ilan-Universität. Copyright: Sosna 